RUNNING HEAD: Explicit Processes from a Usage-Based Perspective

\title{
Explicit knowledge and processes from a usage-based perspective: \\ The developmental trajectory of an instructed $\mathrm{L} 2$ learner
}

\author{
Karen Roehr-Brackin
}

University of Essex

\begin{abstract}
This article considers explicit knowledge and processes in second language (L2) learning from a usage-based theoretical perspective. It reports on the long-term development of a single instructed adult learner's use of two L2 constructions, the German Perfekt of gehen ("go", "walk") and fahren ("go by vehicle"), which was tracked over a period of more than three years. The results indicate that explicit knowledge and processes seemed to have a powerful impact on the participant's L2 learning and use, apparently enabling him to override the predicted bottom-up developmental path in certain circumstances and take a top-down approach instead. Specifically, it was found that the development of fahren was consistent with the predicted trajectory of moving from item-based to more schematic constructions. By contrast, the participant's use of gehen was characterized by schematic constructions almost from the beginning, suggesting a short-cut facilitated by explicit knowledge and processes. Both potential benefits and pitfalls associated with this alternative learning path are highlighted. The findings are explicated with reference to usage-based and complexity/dynamic-systems-theoretic concepts, thus offering an integration of explicit knowledge and processes in L2 learning and use into this particular theoretical framework.
\end{abstract}


Keywords: explicit knowledge and learning; instructed L2 learning; usage-based approach; complexity theory; dynamic systems theory; longitudinal case study

\author{
Author Note \\ Correspondence concerning this article should be addressed to Karen Roehr-Brackin, \\ University of Essex, Department of Language and Linguistics, Wivenhoe Park, Colchester \\ CO4 3SQ, UK. E-mail: kroehr@essex.ac.uk.
}

\title{
Introduction
}

In recent years, applications of a usage-based approach to second language (L2) learning have become increasingly widespread. Researchers argue that a theoretical framework which seeks to integrate the cognitive and social dimensions of human language in use may offer a more comprehensive understanding of the complex phenomenon of language learning than theories with a more narrow focus, such as formalist approaches exclusively concerned with morphosyntactic development or sociolinguistic approaches exclusively concerned with the social functions of language. Theoretical concepts arising from usage-based research into first language (L1) development (MacWhinney, 2004; Tomasello, 2003, 2005) have been fruitfully applied to L2 learning, and the compatibility of the overarching framework of complexity or dynamic systems theory (de Bot, Lowie, \& Verspoor, 2007; Howe \& Lewis, 2005; Larsen-Freeman \& Cameron, 2008) with the usagebased approach has led to a strand of empirical research with instructed L2 learners that focuses on tracing the development of different linguistic constructions over time, employing shared theoretical notions and methodological tools (Eskildsen, 2009, 2012; Spoelman \& Verspoor, 2010; Verspoor, de Bot, \& Lowie, 2011). Applied linguists argue that in (adult) L2 
learning, particularly in instructed settings, both implicit and explicit processes have a role to play, and that both implicit and explicit knowledge are implicated in the development of L2 proficiency (R. Ellis, 2005; 2006; Hulstijn, 2005). While this view appears to be shared by researchers taking a usage-based perspective (e.g., N. Ellis, 2005, 2011), no published work to date has attempted to integrate, empirically as well as theoretically, explicit knowledge and processes into a usage-based framework.

The present study addresses this issue by applying a usage-based approach in order to describe and explain the role of explicit knowledge and processes in the L2 development of an instructed adult learner. The study focuses on the participant's use of L2 German Perfekt constructions involving the verbs gehen ("go", "walk") and fahren ("go by vehicle") in oral interactions with his tutor over the course of several years. The findings suggest that explicit knowledge and processes, directly observable in self-repair moves and metacognitive comments and indirectly inferred from error patterns, influenced the participant's learning and use of these constructions. Moreover, the distinct developmental trajectories that are identified for the two verbs suggest that explicit processes may have functioned as a control parameter, or driving force, in the participant's learning and use of Perfekt constructions with the verb gehen.

\section{The Usage-based Learning Trajectory}

In the usage-based approach, the representation and processing of language is understood in terms of general psychological mechanisms such as categorization and entrenchment. Entrenchment refers to the strengthening of memory traces through repeated activation, so linguistic constructions that are used repeatedly and with high frequency will become highly entrenched (N. Ellis, 2005). Categorization can be defined as a comparison between an established structural unit functioning as a standard and an initially novel target 
structure (Langacker, 2000). To exemplify with reference to real-world concepts, we categorize a coffee table as an item of furniture by comparing its physical and functional attributes with the physical and functional attributes of other items of furniture we are familiar with, such as chairs, desks, kitchen tables and sofas. To exemplify with reference to language, speakers of English categorize table as a noun because of its distributional, functional, and semantic similarities with other nouns, for instance, possible co-occurrence with determiners and plural morphology, and its basic meaning of 'thing' in the most abstract sense as "a bounded region in some domain" (Langacker, 1991, p. 20).

Language learning is initially exemplar-based. Then, as the learner is exposed to an increasing number of exemplars in the course of learning, repeated encounters with known exemplars gradually change the learner's mental representations, allowing for abstractions over instances to be derived (Kemmer \& Barlow, 2000; Taylor, 2002). These abstractions are referred to as schemas, with schema formation defined as "the emergence of a structure through reinforcement of the commonality inherent in multiple experiences" (Langacker, 2000, p. 4). Put differently, a schema emphasizes the commonalities of a number of exemplars while at the same time leaving aside specific differences between them. To exemplify, large numbers of encounters with specific exemplars of words describing actions or events producing observable change (Langacker, 1998) such as go, move, put, make, and so on will eventually allow the language learner to arrive at the schema VERB, based on the commonality inherent in the various exemplars, that is, the fact that they describe a process of one kind or another (this applies to prototypical verbs rather than the entire category). By the same token, a large number of encounters with exemplars such as Laura passed her the book, Harry sends his mother a birthday card, You can fax me the document, and so on will eventually enable the language user to abstract away from the specific differences between 
these constructions and focus on their commonality: the constructional schema of the ditransitive 'X causes $\mathrm{Y}$ to receive Z' (adapted from Goldberg, 1995).

Entrenched constructions, both general and specific, are referred to as conventional units. Accordingly, a speaker's linguistic knowledge can be defined as "a structured inventory of conventional linguistic units" (Langacker, 2000, p. 8). In this context it is worth noting that the usage-based approach takes a maximalistic view of language representation (Eskildsen, 2009), arguing that representations of specific exemplars can be retained alongside more general schemas subsuming these exemplars. In other words, specific and schematic constructions ${ }^{1}$ at varying levels of abstraction exist alongside each other, so that the same linguistic patterns are potentially represented in multiple ways. Hence, linguistic knowledge is represented in a vast, redundantly organized, hierarchically structured network of form-meaning associations. Conventional linguistic units, or constructions, are viewed as inherently symbolic (Kemmer \& Barlow, 2000; Taylor, 2002), that is, constructions at all levels of abstraction are pairings of form and meaning (Goldberg, 2003). Put differently, even entirely abstract schemas have meanings associated with them (e.g., VERB is associated with the meaning of 'process', and the ditransitive ' $\mathrm{X}$ causes $\mathrm{Y}$ to receive $\mathrm{Z}$ ' is associated with the meaning of give.

Usage-based researchers thus argue that language learning is a bottom-up process during which the learner moves from exemplar-based formulas or chunks, that is, entirely specific linguistic constructions (e.g., Laura passed her the book) via item-based schemas (e.g., pass-NP-the book) towards partially or wholly abstract schemas, that is, (more) abstract linguistic constructions (e.g., pass-NP-NP, or the wholly abstract V-NP-NP). This developmental trajectory, which describes an essentially implicit process, has been posited for both L1 (e.g., MacWhinney, 2004; Tomasello, 2003, 2005) and L2 learning (e.g., N. Ellis, 2002, 2011; Eskildsen, 2009). Nevertheless, there are certain differences between L1 and L2 
learning. First and foremost, at the start of L2 learning, the L1 is (by definition) already established - to a greater extent in adults and to a lesser extent in children. Thus, L1 transfer effects can be expected. To begin with, the L2 learner's neural networks are committed to the L1, so s/he starts out with "a parasitic lexicon, a parasitic phonology, and a parasitic set of grammatical constructs" (MacWhinney, 1997, p. 119). In the course of development, the L2 gradually moves towards a status of increasing independence in which direct links between L2 forms and functions are established and referential concepts are restructured (Hernandez, Li, \& MacWhinney, 2005; Jackson, 2007; MacWhinney, 1997, 2012). It is acknowledged that full independence will not necessarily be reached in all domains, and that L1 influence will continue to play a role in most (if not all) L2 learners.

Other important factors in an explanatory account of $\mathrm{L} 1$ effects on second language acquisition (SLA) include the processes of proactive inhibition, overshadowing, and blocking (N. Ellis, 2006). Proactive inhibition refers to the interference of old knowledge in the acquisition of new knowledge. If a certain meaning has been expressed with a particular L1 form for many years, associating that meaning with a new L2 form becomes increasingly difficult. The more entrenched the L1 form, the more challenging the task becomes. Along similar lines, when two cues jointly predict an outcome, the strength of the association that is built up for each cue depends on its salience. If one cue (the L1 form) is more salient than another (the L2 form), it becomes strongly associated with the outcome, while the less salient cue may be overshadowed and blocked, that is, it may be ignored in future learning situations, even though it may be highly relevant (N. Ellis, 2006; N. Ellis \& Sagarra, 2010).

Crucially, in cognitively mature learners the potentially negative effects of L1 entrenchment, proactive inhibition, overshadowing, and blocking, though implicit processes beyond an individual's direct conscious control, may be mitigated and perhaps even be overcome by means of explicit processes. 


\section{Explicit and Implicit Knowledge and Learning}

Explicit knowledge can be defined as knowledge that a learner is consciously aware of and that can be articulated in a verbal statement (Anderson, 2005; R. Ellis, 2004; Hulstijn, 2005). Explicit knowledge can be called up on demand (Dörnyei, 2009). Examples of explicit knowledge relevant to instructed SLA are semantic knowledge, that is, knowledge of the form-meaning pairings underlying vocabulary in L1 and L2, and knowledge of pedagogical grammar rules, that is, metalinguistic propositions describing the form, function, and use of certain L2 constructions. By contrast, implicit knowledge is intuitive knowledge that cannot be brought into awareness or articulated (Dörnyei, 2009; Hulstijn, 2005).

Explicit learning is "characterized by the learner's conscious and deliberate attempt to master some material or solve a problem" (Dörnyei, 2009, p. 136), for example, when the learner looks for regularities in the language input s/he is exposed to. Explicit learning requires effort and strategic expertise, and it results in or makes use of explicit knowledge. In other words, when a learner identifies rules or concepts that capture regularities in the language input s/he has encountered, internally derived explicit knowledge is the result. When a learner makes use of pedagogical grammar rules presented in a textbook or by a teacher, externally provided explicit knowledge is employed. In practice, these two processes most likely go hand in hand (Roehr-Brackin, forthcoming). The term explicit process as used in the present article refers to a speaker's use of explicit knowledge in the context of language comprehension or production, for instance, in the case of monitoring and self-repair (Golonka, 2006). ${ }^{2}$

Conversely, implicit learning is an unconscious, automatic process of induction resulting in intuitive knowledge (Dörnyei, 2009; R. Ellis, 2004). Implicit learning is a relatively slow process that typically requires input over a prolonged period of time. Implicit 
learning results in implicit knowledge, which can be accessed quickly and effortlessly. The language use of a mature L1 speaker is an example of implicit knowledge in action, with both comprehension and production seemingly automatic and executed with ease. Implicit learning is a powerful mechanism, but its success is much more dependent on ample exposure to input than explicit learning. Explicit learning is potentially fast and efficient, allowing for one-trial learning as well as successful learning from minimal input.

In view of these characteristics, it is unsurprising that explicit knowledge and learning have received much attention in instructed SLA research. It has been demonstrated that explicit knowledge about the L2 can be taught to and learned by cognitively mature learners (e.g., Hu, 2011; Macaro \& Masterman, 2006; Scheffler \& Cinciała, 2011), as one would expect. Moreover, research has shown that explicit knowledge is correlated with aspects of L2 proficiency. More specifically, positive relationships between written measures of L2 proficiency and explicit knowledge about the L2 in instructed adult learners have been reported, ranging from moderate (Alderson, Clapham, \& Steel, 1997; Elder, Warren, Hajek, Manwaring, \& Davies, 1999) to strong (Elder \& Manwaring, 2004; Roehr, 2008). ${ }^{3}$ In these studies, explicit knowledge about the L2 was typically operationalized as the ability to correct, describe, and explain errors, that is, as, essentially, the application of pedagogical grammar rules. More recent research has also identified positive correlations between oral measures of L2 proficiency, that is, accuracy and fluency of speech, and explicit knowledge about the L2 (Absi, 2014). Whereas correlation coefficients do not allow us to draw firm conclusions about cause and effect, the potentially facilitative effects of explicit knowledge on L2 performance for cognitively mature learners receiving explicit instruction are by now well established. Explicit instruction in this body of research is typically defined as instruction making use of rule explanation or asking learners to attend to forms and arrive at metalinguistic generalizations on their own (Norris \& Ortega, 2001, p. 167). While the use of 
short, intensive treatments in most existing studies may have led to some bias, favoring learners in explicit conditions. the cumulative finding is confirmed by meta-analyses drawing on large pools of data (Norris \& Ortega, 2001; Spada \& Tomita, 2010) and by more recent research, including some studies where outcome measures of both explicit and implicit L2 knowledge have been employed (e.g., Akakura, 2012).

While cumulative findings clearly point towards the benefits of explicit instruction and, by implication, explicit learning in SLA, it is worth noting that the results from experimental studies typically rely on group means. Moreover, while a range of L2 structures has been investigated, researchers have typically not taken into consideration potential differences between the various constructions under study. There are some exceptions, however, with Elder and Manwaring (2004) pointing out that the typological distance between the L1 and L2 under study may have an impact on the relationship between explicit knowledge and proficiency, and Spada and Tomita (2010) distinguishing between what they refer to as simple versus complex grammatical features in their meta-analysis of the effects of explicit and implicit instruction. Research concerned with learning difficulty (Collins, Trofimovich, White, Cardoso, \& Horst, 2009; DeKeyser, 2005; R. Ellis, 2006; Roehr \& Gánem-Gutiérrez, 2009) has sought to identify what makes particular L2 constructions easy or difficult to acquire. Furthermore, some researchers have argued that the characteristics of linguistic constructions and their associated metalinguistic descriptions may differentially contribute to learning difficulty as implicit knowledge and learning difficulty as explicit knowledge, respectively. Characteristics such as a lack of transparency in form-meaning mappings, with one form associated with several meanings or one meaning associated with several forms, are thought to increase the learning difficulty of L2 constructions as implicit knowledge. At the same time, characteristics such as low truth value of a metalinguistic description, that is, if there are a number of exceptions to a pedagogical grammar rule, are 
expected to increase learning difficulty as explicit knowledge (R. Ellis, 2006; Roehr \& Gánem-Gutiérrez, 2009).

All existing research to date into the role of explicit knowledge and learning has taken either a cross-sectional approach or has relied on relatively short-term quasi-experimental treatments. There appears to be no published research on the role of explicit processes in L2 learning with a longitudinal design, even though such a research design is arguably best placed to offer insights into L2 development.

\section{Usage-based Studies of Instructed L2 Learning}

Two recent investigations into L2 learning by Eskildsen (2012) and Spoelman and Verspoor (2010) are particularly relevant in the present context. They are both longitudinal case studies of instructed adult L2 learners, and they both track the development of specific L2 constructions. Neither of the two investigations focuses on explicit knowledge and learning, but explicit processes may arguably have played a role in the learners' development, as outlined in the following.

Eskildsen (2012) was concerned with the learning of L2 English negation constructions by two L1 Spanish speakers over a period of two (Carlos) and three and a half years (Valerio). The analysis drew on usage-based assumptions of a learning trajectory that starts with exemplar-based constructions and leads to increasingly schematic constructions; this perspective was complemented by a conversation-analytic approach that identified the characteristics of local usage contexts and explored how these interacted with the learners' long-term L2 development. The data set on which the analysis was based consisted of recordings of classroom interactions, that is, the two learners' use of English in an instructed environment. The analysis revealed that the two participants' productive use of English negation developed in accordance with the prediction that recurring exemplar-based 
constructions are gradually generalized, leading to the emergence of more abstract schemas over time. In addition, the developmental patterns were non-linear, as expected, and certain individual differences were uncovered. Interestingly for the present study, Eskildsen noted that one of the participants, Carlos, employed target-like copula negation in the initial stages of learning and thus much earlier than expected (p. 344). The author speculated that this early use of what is typically deemed an advanced construction "may in part be due to the practices of the classroom" (p. 345), that is, instructional input. Later on, Eskildsen made reference to the concept of afforded use (e.g., pp. 350 and 362), that is, the participants' repetition or recycling of input from their teacher or fellow learners in the context of or immediately following classroom tasks. These comments seemingly point towards a potential role for explicit instruction and learning in these participants' L2 development.

Spoelman and Verpoor (2010) presented a longitudinal case study of an L1 Dutch learner of L2 Finnish. The data set consisted of written texts produced by the learner over a period of three years and was analyzed in terms of accuracy and complexity of L2 use. The analytic approach was informed by dynamic systems theory, which predicts a non-linear developmental trajectory of a linguistic system that is in constant flux as a multitude of variables interact with one another. Variability is regarded in this theory as an important characteristic of L2 development, and the authors focused on the participant's intra-individual variability. The accuracy analysis focused on Finnish morphology, which is rich and complex, with a case system comprising no fewer than 15 cases (p. 537). Interestingly for the present study, the authors reported that the learner's error rates were generally low and decreased rapidly over time, with the exception of four cases characterized by high learning difficulty due to a lack of salience, transparency, and frequency in the input. The question arises why the participant coped so well with this difficult learning task, and it seems plausible to speculate that explicit knowledge and learning may have had a role to play. The 
participant was an instructed learner at university level who produced written assignments without time pressure. In other words, optimal conditions for the use of explicit processes were given in this case, although the authors themselves do not mention this possibility.

The two longitudinal studies reviewed above offer tantalizing clues that may hint at a possible influence of explicit knowledge and learning in the participants' L2 development. Neither of the two studies was specifically aimed at investigating explicit processes, so the absence of a discussion of the issue is not highlighted by way of criticism, but rather to argue that usage-based research should begin to consider explicit knowledge and learning as a target for both empirical investigation and theoretical integration. The present study was conducted to achieve this aim.

\section{The Present Study}

The key research issue to be addressed is an examination of the role of explicit knowledge and processes in L2 learning, viewed from a usage-based perspective. In order to gain insight into explicit knowledge and processes, data gathered in an instructed setting that focuses on form and makes use of metalinguistic descriptions are arguably most informative because such a setting provides ample opportunity for the use of explicit knowledge in language comprehension and production. Investigations of L2 development are best served by longitudinal data. In the usage-based approach, the predicted learning trajectory proceeds from exemplar-based to more schematic constructions. In order to uncover evidence that can confirm or disconfirm this developmental path, the analytic focus needs to be on linguistic constructions that allow for at least partially, and ideally entirely, abstract representation.

Accordingly, the present study followed an approach that is similar to the one taken in the two usage-based investigations reviewed above: It is longitudinal in design, relies on detailed data from a single instructed adult participant, and focuses on a particular linguistic 
construction that allows for schematization: the participant's use of the German Perfekt with the verbs gehen ("go", "walk") and fahren ("go by vehicle"). ${ }^{4}$ The following research questions and hypotheses were formulated:

1. How does the learner's use of German Perfekt constructions involving the verbs gehen ("go", "walk") and fahren ("go by vehicle") develop over time?

It was hypothesized that the learner's use of German Perfekt constructions involving the two verbs would develop from reliance on specific constructions or item-based schemas towards greater use of more abstract schemas, as predicted by the usage-based approach.

2. What evidence is there for (a) erroneous use and (b) self-repair or any other use of explicit knowledge in connection with these constructions?

It was hypothesized that there would be more extensive evidence of (a) erroneous use and (b) self-repair or any other use of explicit knowledge in connection with Perfekt constructions involving the verb gehen than with those involving the verb fahren. The rationale for this second hypothesis will be detailed below.

\section{Method}

\section{Participant}

The participant, H, was an L1 (British) English adult male in his forties. At school, $\mathrm{H}$ had learned German for 3 years and French for 1 year. Prior to this, he had acquired basic Arabic in an immersion setting over a period of 3 years. In his adult life, $\mathrm{H}$ did not engage in any language study until he resumed his learning of German 6 months before data collection for the present study began. Learning took place in the context of weekly or fortnightly oneto-one German classes with myself, the researcher, as tutor ${ }^{5}$ and supplemented by self-study activities. Beyond engaging with L2 learning materials during self-study and having very 
occasional conversations with German speakers of his acquaintance, $\mathrm{H}$ went on five trips to German-speaking countries lasting 7-10 days each during which he had naturalistic exposure to the $\mathrm{L} 2$.

\section{The Longitudinal Data}

The data set consisted of 85 audio-recordings of oral learner-tutor interactions taking place during class time. It covered a learning period of 3 years and 4 months in total. Data were collected in two parts, with Part 1 comprising recordings 1 to 56 over a period of 17 months, followed by a break of 11 months when classes continued but no recordings were made, ${ }^{6}$ and concluding with Part 2, which comprised recordings 57 to 85 over a period of 12 months. During the data collection period, a part of each class was audio-recorded, as described below. The resulting 85 audio recordings amounted to a total length of just over 21 hours, with a range from $8 \frac{1}{2}$ to 31 minutes and a mean length per recording of just under 15 minutes. All recordings were transcribed into CHAT format and coded and analyzed with the help of the CLAN program of the CHILDES database (MacWhinney, 2000).

In each of the recordings, as part of the class, I asked $\mathrm{H}$ to report what he had done the day before. The rationale for using the same prompt throughout the data collection period was twofold. First, it was meant to ensure that certain L2 constructions would occur in each recording, so long-term development could be tracked. The second reason for using the same prompt was to reduce the cognitive load of the task. $\mathrm{H}$ had to recall the events of the previous day; as classes (and thus recordings) typically took place at the weekend, events of the previous day varied from week to week, apart from routine activities such as getting up or having something to eat. In addition to calling up a sequence of episodic memories, he had to describe these memories in the L2 orally, that is, in real time. The initial prompt of 'What did you do yesterday?' was followed up with comments and questions after $\mathrm{H}$ had begun 
recounting his experiences. The follow-up questions were not pre-planned and varied from session to session, in accordance with the topics arising in the participant's report. ${ }^{7}$

$\mathrm{H}$ was expected to do most of the talking during the recorded sessions, with myself (the tutor and researcher) responding to the learner's utterances and providing input and feedback as needed. This set-up was intended to ensure a constant interplay of explicit and implicit processes. On the one hand, the oral modality of the task resulted in pressure on the participant to produce spoken output in real time - a situation that encouraged the use of any available implicit knowledge. On the other hand, the participant was exposed to explicit instruction (see below) as well as input and feedback from the tutor during the oral interactions, all of which should encourage focus on form and the use of any available explicit knowledge.

\section{The Instructional Environment of the Classes}

In his first German language classes with me 6 months before recordings began, $\mathrm{H}$ indicated that he wished to start at the very beginning, since he felt he did not remember anything from his German classes at school. Although no formal proficiency measure was administered, my impression during the first classes was that starting at the beginning was appropriate: H recognized some words, but had otherwise no apparent foundation in German.

In class and for self-study purposes, we used commercial textbooks, starting with Willkommen! (Coggle \& Schenke, 1998), a beginner-level general-purpose course for adult learners often employed in evening classes or other non-specialist language courses. This was followed by the Passwort Deutsch series, starting with Volume 2 (Albrecht et al., 2001). The series is more academically oriented and typically used in tertiary-level language courses. All textbooks were accompanied by audio materials and offered practice in all four skills, in addition to grammar-focused exercises and metalinguistic descriptions in the form of 
pedagogical grammar rules. $\mathrm{H}$ also used complementary learning materials, such as additional listening exercises, edited works of literature, and magazine articles. In sum, $\mathrm{H}$ was exposed to explicit instruction with in-class activities focused on practicing grammar, vocabulary, speaking, listening, and reading. There was relatively little focus on (extended) writing, although $\mathrm{H}$ completed written grammar exercises on a regular basis, especially in self-study time.

\section{Targeted L2 Constructions}

As the participant's task in the recorded sessions was to talk about what happened the day before, there were ample references to past events in the data set. In spoken German, the Perfekt tense is typically used to render past events. The Perfekt forms of the verbs gehen ("go", "walk") and fahren ("go by vehicle") were the two most frequently occurring exemplars of Perfekt constructions in the data set, with well over 300 tokens each. Thus, the development of Perfekt constructions involving the verbs gehen and fahren was chosen as the analytic focus.

Taking a very rough metric, in a large bilingual dictionary (Terrell, Schnorr, Morris, $\&$ Breitsprecher, 1999), about three and a half columns are dedicated to listing the various meanings of gehen and expressions involving gehen, while about two columns are dedicated to fahren and expressions involving fahren, suggesting that both verbs are highly polysemous. A highly proficient speaker of German exhibiting target-like use of the two constructions can be assumed to have knowledge of and fast access to: (a) most or all possible meanings of the verbs gehen and fahren; (b) the past participle forms associated with the two verbs, that is, gegangen and gefahren, as well as their association with a finite form of the auxiliary verb sein (be) in German Perfekt constructions; (c) specific constructions and/or item-based schemas of highly frequent expressions involving gegangen and gefahren; 
and (d) abstract schemas involving fully formed associations of most or all conventionally sanctioned usage contexts of gegangen and gefahren.

In a highly proficient speaker, these comprehensive knowledge representations are likely to be accessed above all via implicit processes. A proficient speaker's comprehensive knowledge also remains implicit as a learning target for L2 learners because instructed learners are not normally told explicitly about all possible meanings of the two verbs or asked to try to learn all of these meanings at once through studying the entries in a large bilingual dictionary. By the same token, learners would not normally encounter all possible usage contexts at once. Instead, textbooks and teachers typically present them with a somewhat less daunting, more manageable explicit learning target consisting of metalinguistic information and examples provided step-by-step at different points in the course of learning. I took the same approach in H's classes. For reasons of space, readers are referred to Appendix S1 of the Supporting Information online for a detailed description of the instructional approach and progression I followed when dealing with the Perfekt in the classes over the total instructional period of 3 years and 4 months.

If the descriptions of the targeted constructions given above are considered in terms of learning difficulty (R. Ellis, 2006; Roehr \& Gánem-Gutiérrez, 2009), it seems that Perfekt constructions involving gehen may be more difficult than Perfekt constructions involving fahren. Although both verbs have a number of meanings and appear in a variety of expressions, gehen is more polysemous than fahren. Moreover, the past participle form gegangen is less transparent than the form gefahren, which can be traced back more easily to the infinitive form. Finally, and perhaps most importantly, while gehen and its English translation equivalent go are clearly cognates, the meaning of gehen is more restricted than the meaning of go because German captures the "go-by-vehicle" dimension by means of fahren. In other words, an English-speaking learner needs to form a separate conceptual 
category comprising meanings associated with fahren, while simultaneously associating with gehen a restricted version of his/her existing conceptual category comprising meanings associated with go. In view of an English speaker's entrenched L1 knowledge, the phenomenon of proactive inhibition will make this process difficult (N. Ellis, 2006; N. Ellis \& Sagarra, 2010). Thus, overgeneralization errors arising from the use of gehen, even if fahren would be the appropriate lexical choice, can be expected. Conversely, overgeneralization of fahren to contexts in which gehen would be the appropriate lexical choice are less likely. In other words, given the expected parasitical status (Hernandez et al., 2005; MacWhinney, 1997, 2012) of gehen in relation to go and its associated cluster of meanings, L1 entrenchment may well cause considerable interference in this case, whereas fahren constitutes a new cue which should have no separate memory trace associated with it yet.

When difficulties in L2 comprehension or production arise, a learner may make more errors. At the same time, a learner may bring to bear explicit processes (N. Ellis, 2002; 2005), including deliberate analysis of input (e.g., "Where is the verb in this sentence? Who is performing the action? Is this the subject or the object?"), step-by-step construction of output (e.g., "The Perfekt is a compound tense, so the auxiliary verb should be in second place and the participle in last place: Gestern bin ich ins Kino gegangen - "Yesterday I went to the cinema"."), comparative metalinguistic reflection on L1 and L2 conventions (e.g., "In German, you typically use the Perfekt to talk about events in the past, while in English you typically use the simple past."), monitoring, and self-repair. In general, in the case of greater learning difficulty, a larger number of errors as well as more extensive use of explicit knowledge may be expected.

\section{Analytic Procedures}


In order to answer the research questions, a qualitative analysis of all relevant learner utterances was undertaken. Relevant utterances were all learner-initiated utterances (i.e., repetitions and rehearsals of immediately preceding tutor input were excluded) in the Perfekt tense involving gehen or fahren, including any verb forms with separable particles, for instance, los (indicating "setting off to a destination”), weiter (“on”, “further”), zurück (“back"), spazieren (“walking or travelling for pleasure"). All relevant utterances were extracted from the data set together with their immediate context. First, they were scrutinized individually in order to identify changing patterns of use over time (RQ1) that might indicate change from reliance on specific constructions or item-based schemas towards greater use of more abstract schemas, as predicted by the usage-based approach. To illustrate, an example of an item-based schema is 'Subj aux in die Stadt gefahren' ('Subj aux gone to town'); an example of an abstract schema is 'Subj aux ([adverbial]) [preposition] [location] ([particle]) gegangen'. Second, any evidence was also sought of (a) erroneous use and (b) self-repair or any other use of explicit knowledge (RQ2). This included metalinguistic reflections or comments as well as behavior indicative of the step-by-step construction of utterances, such as hesitant production, questioning intonation and/or requests for feedback.

In accordance with a qualitative approach, analytic induction was used to arrive at a detailed narrative account supported by extensive exemplification. Thus, the presentation of results makes use of thick (or rich) description (Duff, 2008; Flyvbjerg, 2004; Ryan \& Bernard, 2000) rather than statistical measures. The analytic approach was a combination of top-down and bottom-up processes to ensure conceptual coherence (Miles \& Huberman, 1994). The top-down process was informed by the hypotheses formulated above, that is, a particular learning path was predicted, and the concepts of erroneous use, self-repair, hesitant production, and metalinguistic reflections/comments were pre-specified. The bottom-up process was data-driven: By scrutinizing and comparing all the relevant utterances 
repeatedly, both within a particular construction (Perfekt with gehen and Perfekt with fahren separately) and across both constructions, I searched for instances that provided evidence in support or in contradiction of the hypotheses.

The description of the learner's developmental trajectory (RQ1) refers to five developmental stages. This is done purely for presentational reasons, that is, to ensure readability of the results. Essentially, a stage constitutes a unit summarizing the participant's inventory of Perfekt constructions with gehen and fahren at that point in time. It is acknowledged that the decision of how many stages or summary units to posit was subjective; fewer or more could have been chosen. However, the number of stages in itself has no material impact on the results, as will become clear below, and it has no theoretical significance.

\section{Results}

\section{Long-term Development of Perfekt Constructions with gehen and fahren}

In what follows, in order to answer the first research question, H's developmental trajectory is described and illustrated by means of selected examples. Each data example is given below with an indication of the class in which it occurred, that is, Session 1, Session 2, and so on, and shown as S1, S2, etcetera in parenthesis. STU refers to the learner, TEA to the tutor. ${ }^{8}$ Further examples can be found in Appendix S2 online (for Perfekt constructions with fahren) and Appendix S3 online (for Perfekt constructions with gehen).

With regard to Perfekt constructions with the verb fahren, the analysis resulted in the identification of a developmental sequence from initially item-based constructions to gradually more abstract constructional schemas based around the past participle gefahren. For presentational purposes, the developmental sequence is divided into five stages. As indicated 
above, a greater or smaller number of stages could have been selected in principle, but this in itself would have had no bearing on the key finding that emerged from the analysis, namely, that H's developmental path seemed to follow the predicted trajectory. A summary in table format of the development of the constructional schemas A, B, C, and D referred to in the presentation of results for RQ1 below is shown in Tables 1 to 4.

(Insert Tables 1- 4 here.)

Two item-based constructions are in evidence from the beginning of the data collection period (S2-S5; H did not use a Perfekt construction with fahren in Session 1). The nach-location/nach-Hause construction (A) occurs with subject-auxiliary word order as in Example 1 below as well as with inverted word order with an adverbial in first position as in Example 2 (see Table 1, Stage 1). The in-die-Stadt construction (B) is anchored around this particular exemplar in Example 3 (see Table 2, Stage 1):

(1) STU: Wir sind nach E. [name of town] gefahren. (S2)

We went/drove to E.

(2) STU: Und dann sind wir zurück nach Hause gefahren. (S3)

And then we went/drove back home.

(3) STU: Wir sind in die Stadt gefahren. (S4)

We went/drove into town.

From S6 to S17, the separable particles weiter (indicating "going on") and los (indicating "setting off") begin to appear in a more idiomatic position in the nachlocation/nach-Hause construction (A), that is, attached to the main verb, as in Example 4 (see 
Table 1, Stage 2), rather than following the auxiliary. The latter is a position that is idiomatic for the particle zurück ("back"), less so for weiter, and least of all for los:

(4) STU: Um halb drei bin ich nach C. [name of town] losgefahren. (S7)

At half past two I left for C.

The tutor regularly corrects H's use of los following the auxiliary, but mostly accepts weiter in the same position without providing any corrective feedback. Looking ahead to future uses, it can be noted that los as a separate particle following the auxiliary gradually disappears from H's speech. On those occasions when los does occur in this unidiomatic position, it is always in the context of the nach-location/nach-Hause construction, which is later replaced by a more abstract schema. In other words, it seems that $\mathrm{H}$ formed an early association between los following the auxiliary and the nach-location/nach-Hause construction. This 'relic' pattern with unidiomatic placement of los following the auxiliary is last used in S70.

In the second developmental stage, the means-of-transport construction $(\mathrm{C})$ emerges (see Table 3, Stage 2), as in Example 5:

(5) STU: Wir sind mit dem Bus *von Flughafen *nach in der Nähe vom Hotel gefahren. (S8)

We took the bus from the airport to near the hotel.

This construction enables $\mathrm{H}$ to specify the means of transport used for travel as well as the point of departure and the destination of travel, with $z u$ ("to") allowing for the specification of destinations other than geographical locations, which require the preposition nach ("to"). However, H still seems to rely heavily on Construction A, attempting to express new meanings with this pattern. Utterances with the preposition $z u$ indicating destinations 
appear to be tied to Construction $\mathrm{C}$ at this stage; they are still quite rare at this point and almost always erroneous in one way or another.

From S18 to S25, Construction A is generalized to include the preposition $z u$ (see Table 1, Stage 3). Correct uses of $z u$ within the constructional schema appear more regularly (Example 6), and $z u$ and nach are correctly combined as well:

(6) STU: Danach sind wir zu B. [name of shop] gefahren. (S23) Then we went/drove to B.

Nevertheless, $\mathrm{H}$ still seems to be uncertain as to whether $z u$ or nach is required to express specific meanings, with erroneous uses of nach with non-geographical locations still persisting. In this sense, the two prepositions appear to constitute bimodal attractors ${ }^{9}$ in the participant's system (Larsen-Freeman \& Cameron, 2008).

Use of the in-die-Stadt construction (B) with adverbial in first position and subjectauxiliary inversion can be observed for the first time (see Table 2, Stage 3), as in Example 7:

(7) STU: Um halb elf vielleicht sind wir in die Stadt losgefahren. (S22)

At half past ten perhaps we set off into town.

Construction $\mathrm{C}$ does not re-occur either at this or future stages; the reason for this seems to be above all that there was no need to mention the means of transport used because it was typically evident from the preceding context.

From S26 to S50, prepositions other than nach and $z u$ appear in Construction A (see Table 1, Stage 4), suggesting further generalization (Example 8):

(8) STU: Dann sind wir zurück ins Dorf gefahren. (S26) Then we went/drove back into the village. 
Nach Hause (home, directional meaning), up to this point apparently treated as a chunk, is broken up, with $z u$ (incorrectly) replacing nach for the first time. Thus, Construction A can now be relabeled preposition-location construction. The in-die-Stadt construction (B) could theoretically be incorporated under Construction A, but it seems to remain a strong attractor in its own right (Example 9 below), suggesting a separate, itembased representation. The drive construction (D) occurs for the first time at this stage (see Table 4, Stage 4), that is, fahren is used as an intransitive verb in the sense of drive (a car) (Example 10 below). Use of this construction remains rare; it is used productively only three times and always with an incorrect auxiliary:

(9) STU: Und danach sind wir in die Stadt gefahren. (S37)

And then we went/drove into town.

(10) STU: Du *hast gefahren. (S27)

You were driving.

In the final developmental stage from S51 onwards, the preposition-location construction (A) with subject in first position is extended further to include adverbials placed after the auxiliary verb (see Table 1, Stage 5; Example 11 below). By the same token, the drive construction (D) is used for the first time with an added adverbial after the auxiliary verb (see Table 4, Stage 5; Example 12 below). The in-die-Stadt construction (B), still in regular use, appears to remain a constructional island:

(11) STU: Wir sind zuerst zu einer Tankstelle gefahren. (S51)

We first went/drove to a petrol station.

(12) STU: Ich *habe nie in N. gefahren. (S51)

I've never driven in $\mathrm{N}$. 
In summary, the results suggest that H's developmental trajectory followed the predicted learning path in the case of Perfekt constructions with fahren, showing a gradual progression from initial reliance on a small number of item-based constructions towards more varied use of both a greater number of constructions and more abstract constructional schemas. A frequently used item-based construction (B) occurs regularly throughout the data set, suggesting that it may have a separate, redundant mental representation.

With regard to Perfekt constructions with the verb gehen, the main finding is that the analysis did not yield a developmental sequence from initially item-based constructions to gradually more abstract schemas based around the past participle gegangen. Instead, in marked contrast to Perfekt constructions with fahren, there was evidence of schematic constructions being used almost from the start, leaving little room for further abstraction over time and thus for the expected developmental sequence to be observed.

Two abstract constructional schemas labeled the preposition-location construction (A) and the walk construction (B) were in use by Session 8. The latter (see Example 19 shown later), like its counterpart the drive construction, is rarely used. It is worth noting that both constructional schemas are entirely abstract, with no specific items represented, except of course the past participle gegangen itself (or idiosyncratic equivalents of the form such as gegehen), as shown in Table 5.

\section{(Insert Table 5 here.)}

Examples 13 to 18 , all deliberately taken from early sessions, show the considerable variety of items used in the adverbial, preposition, and location slots in the prepositionlocation construction (A); varied use of separable particles is likewise in evidence almost from the very beginning: 
(13) STU: Danach sind wir zu T. [name of shop] gegangen. (S1)

Afterwards we went to T.'s.

(14) STU: Dann sind wir wieder zurück zum Auto gegangen. (S3)

Then we went back to the car.

(15) STU: So sind wir zurückgegangen (...) und in der Nähe am Wasser spazierengegangen. (S6)

So we went back and went for a walk nearby along the water.

(16) STU: Später sind wir in der Nähe vom Hotel spazierengegangen. (S8)

Later we went for a walk near the hotel.

(17) STU: Wir sind in der Stadt spazierengegangen. (S4)

We went for a walk in the city.

(18) STU: Ich bin in die Küche gegangen. (S6)

I went into the kitchen.

(19) STU: Wir sind um drei Meilen gegangen. (S8)

We walked about three miles.

It is perhaps interesting to note that although abstract constructional schemas are observable almost from the start, Perfekt constructions with gehen are generally used less frequently in Part 2 of the data set (S57 to S85 over 12 months) than in Part 1 (S1 to S56 over 17 months; it will be remembered there was an 11-month period in between, when classes continued but no recordings were made). As H's speech becomes more idiomatic in the course of development, early, less idiomatic Perfekt constructions with gehen are replaced by different constructions, as modeled repeatedly by the tutor. An example is the use of a gehen construction to express going (in)to a shop. Though acceptable in the L2, this construction is abandoned in favor of the construction Subj [form of sein] bei [name of shop], such as in the sentence Wir waren bei [name of shop] ("We were at [name of shop]"), which is preferable in 
German. Conversely, "We went to [name of shop]", the translation equivalent of the Perfekt construction with gehen, is of course preferable in English.

With regard to the first research question, it was hypothesized that the learner's use of German Perfekt constructions involving the verbs gehen ("go", "walk") and fahren ("go by vehicle") would develop from reliance on specific constructions or item-based schemas towards greater use of more abstract schemas, as predicted by the usage-based approach. The findings support this hypothesis with regard to the verb fahren, but not with regard to the verb gehen.

\section{Erroneous Use and Use of Explicit Knowledge}

The second research question asked about evidence for (a) erroneous use and (b) selfrepair or any other use of explicit knowledge as indicated by metalinguistic reflections or comments, hesitant production, questioning intonation or requests for feedback in connection with German Perfekt constructions involving the verbs gehen and fahren.

With regard to Perfekt constructions with fahren, $\mathrm{H}$ displays semantically and pragmatically appropriate use throughout the data set. He almost always uses the correct participle form gefahren, with very occasional self- or tutor correction from fahren to gefahren. With respect to choice of auxiliary verb in the Perfekt construction, $\mathrm{H}$ mostly uses a form of sein, that is, the target-like auxiliary. The error rate of $6 \%$ is relatively low and very similar to the mean error rate of $6.2 \%$ for all Perfekt constructions in the data set. Scrutiny of instances of erroneous auxiliary choice in Perfekt constructions with fahren suggests that non-target-like use occurs in three distinct scenarios.

The first error scenario pertains to utterances involving coordinating clauses and thus more than one verb; that is, in addition to gefahren, the utterance contains another verb in the 
Perfekt. H then either inappropriately omits the auxiliary with the second verb, even though it is different from the auxiliary combining with the first verb and therefore cannot be omitted, or he inappropriately uses a form of haben, as shown in Example 20:

(20) STU: So sind wir zurück zum Auto gegangen, und wir *haben zurück nach C. [name of town] gefahren. (S34)

So we went back to the car, and we went/drove back to C.

The second error scenario occurs at the point of abstraction of constructional schemas to include new prepositions, adverbials in new positions, or new separable particles, or when a completely new constructional schema is first employed. Examples 21 and 22 show early instances of use of the prepositions $z u$ ("to") and durch ("through") in the prepositionlocation construction:

(21) STU: Wir *haben zurück zum Hotel gefahren. (S5)

We went back to the hotel.

(22) STU: Wir *haben durch C [name of town] gefahren. (S49)

We went/drove through $\mathrm{C}$.

The third error scenario refers to apparently complex discourse contexts and/or situations in which $\mathrm{H}$ is struggling to recall a particular episodic memory, as in Example 23:

(23) STU: Und dann [/] erm [^ pause] dann *haben wir, erm, zurück nach C. [name of town] gefahren.

And then we went/drove back to $\mathrm{C}$.

STU: No, we didn't, did we? (S53)

It would appear that all three error scenarios have one thing in common: H's cognitive resources are stretched, and his attention is focused not on auxiliary choice, but on other 
verbs in the utterance, on the selection of new items for insertion into an open slot, on the use of an entirely new construction, or on the retrieval of a particular episodic memory in order to satisfy the communicative dimension of the interaction task.

Instances of self-correction can be found throughout the data set, but at around $4 \%$ the self-correction rate is low. As the error rate is likewise low, this is not unexpected. A selfcorrection is shown in Example 24:

(24) STU: Wir *haben zu einer Kneipe gefahren [//] wir sind zu einer Kneipe gefahren. (S30) We went/drove to a pub.

With regard to Perfekt constructions with gehen, H mostly displays semantically and pragmatically appropriate use, although there is occasional self- or tutor correction from gegangen to gefahren. This suggests possible L1 interference, as anticipated, with gehen, the phonologically and orthographically closest cognate of English go, overgeneralized to fahren contexts. ${ }^{10} \mathrm{H}$ mostly uses the correct participle form, but there is some self- or tutor correction from gehen to gegangen as well as occasional use of the idiosyncratic form *gegehen with subsequent self- or tutor correction.

Regarding choice of auxiliary in Perfekt constructions with gehen, $\mathrm{H}$ mostly uses a form of sein, that is, the target-like auxiliary (auxiliary "be"). Uses of non-target-like haben (auxiliary "have") can be observed, however, and at 18\% the error rate is three times higher than the error rate observed with fahren. Scrutiny of instances of erroneous use in Perfekt constructions with gehen suggests that non-target-like choice of auxiliary occurs in situations that are broadly comparable to the error scenarios identified above for the verb fahren. 
The first error scenario pertains to utterances involving coordinating clauses, as described above. In addition to gegangen, the utterance contains another verb in the Perfekt that takes the auxiliary haben. $\mathrm{H}$ then either inappropriately repeats haben or inappropriately omits the auxiliary with the second verb (gegangen), as in Example 25:

(25) STU: Ich habe zwei oder drei kleine Brötchen gegessen und (*) dann zurück zur Arbeit gegangen. (S19) I ate two or three small rolls and then went back to work.

The most frequent error scenario refers to situations where there appears to be strong competition for cognitive resources, with H's attention focused on issues other than auxiliary choice. With abstract schemas in use almost from the start, a wide range of expressions can potentially fill the various constructional slots, and choices of preposition, grammatical gender, case and case inflections as well as choices of semantically and pragmatically appropriate lexical items need to be made. In addition, episodic memories must be retrieved to complete the communicative dimension of the task. Hesitation phenomena accompany such cases, as in Examples 26 to 28. The unfilled pause in Example 26 suggests that $\mathrm{H}$ may have been thinking about what actually happened at the time, at the cost of focusing on auxiliary choice:

(26) STU: Wir *haben, erm, [unfilled pause] in der Nähe spazierengegangen. (S8) We went for a walk nearby.

The retracing and self-repair operations in Example 27 indicate that the learner's attention may have been focused on selection of the appropriate preposition (von), gender (masculine der) and case (dative - dem), as the utterance is constructed incrementally in real time: 
(27) STU: Wir *haben, erm, von [/] von der [//] *den Bahnhof, erm, spazierengegangen. (S8)

We went for a walk from the station.

The retracing move and follow-up question in Example 28 suggest that $\mathrm{H}$ was searching for a suitable lexical item, at the cost of appropriate auxiliary choice, and with no determiner being produced for the (idiosyncratic) noun Besuchzentrum:

(28) STU: Und dann sind wir zurück zum Auto, und <wir *haben> [/] wir *haben in *Besuchzentrum gegangen.

And then we went back to the car and we went into the visitor center. STU: What do you call it? (S46)

It was pointed out above that $\mathrm{H}$ used Perfekt constructions with gehen less frequently in later sessions, as more idiomatic alternatives were gradually gaining ground.

Correspondingly, there are also noticeably fewer auxiliary errors in later sessions, with almost all errors falling into the coordinating-clauses category. In addition, however, a third error scenario emerges. It refers to H's attempts to generalize the construction Das geht (nicht) ("That is (not) alright"; "that works (doesn't work)") to a past context by rendering it in the Perfekt tense. This is shown in Examples 29 and 30:

(29) STU: Erm, aber das geht nicht, erm, oder das *hat nicht gegangen? (S77) But that doesn't work, or that didn't work?

(30) STU: Erm, <ich denke, das geht> [//] das [///] ich denke, das *hat schon gut gegangen? (S83)

I think that goes, that, I think that went alright? 
The rising intonation at the end of the utterances indicates that $\mathrm{H}$ was quite aware of being in uncharted waters. Unbeknown to him, even with the correct auxiliary, use of the construction Das geht (nicht) in the Perfekt tense is unconventional in German; instead, the idiomatic choice of tense would be Präteritum (Das ging (nicht)). If this fact is considered in conjunction with the hesitant manner of production and the implied requests for feedback, there appears to be rather strong evidence for the use of explicit knowledge in this case. Drawing on the pedagogical grammar rules he was familiar with, the participant, deliberately and step-by-step, constructs a novel utterance that, though ultimately unidiomatic, complies with (some of) the metalinguistic descriptions he has encountered.

As in the case of fahren, instances of self-correction in Perfekt constructions with gehen (Example 31 below) can be found throughout the data set. At 9\%, the self-correction rate is higher than for Perfekt constructions with fahren, but given that the error rate is likewise higher, this is not unexpected:

(31) STU: <Dann *haben wir> [//] dann sind wir alle zusammen zurück zum Parkplatz gegangen. (S70) Then we all went/walked back to the car park together.

Last but not least, it seems that $\mathrm{H}$ was well aware of his occasional difficulties with auxiliary choice in the context of Perfekt constructions with gehen, as illustrated in Examples 32 and 33:

(32) STU: Und <wir *haben, erm, durch die Stadt gegangen $>[/ /]<$ wir sind $>[/]<$ wir sind $>$ [/] whoops, damn, wir sind durch die [laughs] Stadt gegangen. (S40)

(33) STU: Und wir *haben, erm, durch das Dorf, erm, gegangen.

TEA: Mhm, wir sind, ja. 
STU: Ah, what, I didn't say it again?! (S41)

With regard to the second research question, it was hypothesized that there would be more extensive evidence of (a) erroneous use and (b) self-repair or any other use of explicit knowledge in connection with Perfekt constructions involving the verb gehen than the verb fahren. The findings confirm this hypothesis. Both errors and self-corrections occurred more frequently with gehen than with fahren. As for use of explicit knowledge beyond self-repair, the analysis revealed indirect but nonetheless compelling evidence for the use of explicit processes primarily in connection with gehen, as exemplified by H's apparent real-time application of explicit knowledge in order to construct a Perfekt version of Das geht (nicht) and his metacognitive awareness of difficulties with auxiliary choice.

\section{Discussion}

The findings arising from the present qualitative analysis of the long-term development of Perfekt constructions with the verbs gehen and fahren were suggestive of explicit processes at play in H's L2 learning. There was apparent use of explicit knowledge during the construction of specific utterances, and instances of self-repair as well as the patterning of auxiliary choice errors provided further (albeit indirect) evidence of explicit knowledge in use. Self-correction indicates that the participant was monitoring his own output - a quintessentially explicit process. In addition, errors in auxiliary choice occurred primarily when there appeared to be strong competition for attentional resources, that is, when the learner struggled to recall specific episodic memories, when a sentence contained coordinating clauses and thus more than one verb, or when more abstract constructional schemas were (first) used and the various open slots had to be filled. With H's attention focused on these processes, as indicated by hesitation phenomena such as filled and unfilled pauses or retracing moves, errors occurred, suggesting that with cognitive capacities stretched 
to the limit, the explicit processes required for ensuring correct auxiliary choice could not operate successfully. The learner's own metacognitive comments provide additional proof of a high level of awareness.

Certain differences were in evidence in the results obtained for Perfekt constructions with gehen and fahren. In the case of fahren, a bottom-up developmental trajectory moving from initial use of a limited number of item-based constructions towards use of more varied and more abstract schemas, alongside a frequent item-based construction, was observed. By contrast, in the case of gehen, fully abstract constructional schemas were in use practically from the start. This strongly suggests the possibility of top-down learning based on explicit knowledge and processes.

The explicit knowledge in question may have been internally derived or externally provided; in practice, it was probably a combination of both. The participant was exposed to explicit instruction drawing on pedagogical grammar rules, which essentially present simplified schemas in the form of propositions amenable to explicit processing, aimed at aiding learners in their endeavor to gain cognitive control over (some aspects of) the L2. In addition, $\mathrm{H}$ was aware of the lexical semantics of gehen and fahren, with the former assuming cognate status in relation to English go and the latter requiring the formation of a new form-meaning association. As argued above, the parasitic relationship of gehen and go, alongside the phenomena of proactive inhibition, overshadowing and blocking, may have induced cross-linguistic transfer. Such transfer would manifest itself in the top-down application of an L1 schema to the L2, as suggested by the use of the German translation equivalent of go to [name of shop], a construction which is gradually replaced by a more idiomatic alternative that does not involve the use of the verb gehen. 
In sum, the observed developmental sequence for Perfekt constructions with gehen indicates that the participant may have used top-down processes based on explicit knowledge, in combination with L1 transfer, to effectively override the expected implicit, bottom-up learning trajectory. Regarding L1 transfer, it seems possible that $\mathrm{H}$ made use of translation, which is essentially a specific application of explicit knowledge: When translating, we conceptualize an L1 utterance reflecting a certain meaning; we then proceed to transforming the utterance into L2, step by step, making comparisons and monitoring carefully, trying to make sure that the $\mathrm{L} 2$ construction uttered not only reflects the intended meaning, but also conforms to the formal conventions of the $\mathrm{L} 2$.

It seems that the alternative top-down learning path is associated with advantages as well as disadvantages, however. On the one hand, the use of abstract constructional schemas from the beginning allows for the expression of more varied meanings, so - potentially at least - more target-like language use can be achieved. On the other hand, abstract constructional schemas have a large number of open slots. If these slots are filled, step by step, with the help of explicit, controlled processes, L2 use becomes cognitively very costly. With no entrenched item-based constructions to fall back on via implicit, automatic processes, and with various lexical, morphological, and pragmatic choices to be made, pedagogical rules to be applied, and output to be monitored, attentional resources may be stretched, sometimes overstretched. If the learner thus occasionally punches above his weight, as it were, one would expect precisely the results that were identified in the case of Perfekt constructions with gehen: more instances of erroneous use and, to compensate for this, more frequent self-correction than in the case of fahren.

\section{Conclusion}


The present findings support the argument that the participant, an instructed adult, made use of explicit knowledge and processes in his L2 learning and performance. This in itself is relatively uncontroversial, given that there is empirical support available for a role of explicit learning in (adult) SLA (R. Ellis, 2005; Hu, 2011; Macaro \& Masterman, 2006; Norris \& Ortega, 2001; Scheffler \& Cinciała, 2011; Spada \& Tomita, 2010). Nevertheless, the contribution is unique insofar as empirical evidence of explicit processes in action is rarely presented in instructed SLA studies, as in the present case, and conceptual integration into a usage-based framework seems to be as yet entirely absent in the field. A main limitation that must be acknowledged, however, is the fact that all data were gathered from a single participant. While this inherent drawback of case study research is mitigated by the fact that the cognitive processes under investigation should apply to all (literate) adult learners, individual differences between learners in terms of the extent to which they rely on explicit knowledge and processes can be expected. Therefore research investigating these phenomena in instructed L2 learning with different participants would be desirable. Moreover, the participant in the present study learned an L2 that is typologically close to his L1 - a circumstance which may have encouraged both L1 transfer and comparative analysis of L1 and L2 constructions at the explicit level. Other, more distant L1-L2 combinations may yield quite different results in this respect and therefore deserve further investigation, ideally in the context of a longitudinal design.

The findings of the present study support the view that explicit processes are not only real, but also potentially very powerful, allowing the learner to side-step the expected developmental trajectory in certain situations. From a theoretical perspective, explicit knowledge and the application of such knowledge during L2 learning and use can be understood in terms of the concept of control parameters or driving forces. In complexity/dynamic systems-theoretic terms, factors that have a potentially strong influence 
to the extent that they can bring about phase transitions, that is, qualitative shifts in behavior, are referred to as driving forces (Howe \& Lewis, 2005) or control parameters (LarsenFreeman \& Cameron, 2008). Functioning as a control parameter, it seems that explicit knowledge and processes can ensure that the L2 system develops continually by keeping it away from undesirable attractor states; this is achieved by means of monitoring and selfrepair as well as by the deliberate construction of utterances that are in keeping with pedagogical grammar rules and thus (hopefully) target-like. The findings regarding gehen constructions suggest that explicit knowledge and processes can bring about genuine phase shifts, that is, a qualitative change in system behavior which in this case manifested itself as a departure from the bottom-up learning path. According to Larsen-Freeman and Cameron (2008), "control parameters are the key to understanding change in complex systems - if they can be identified, then we know what drives the system" (p. 54). It appears that a control parameter has been identified in this instance: In H's L2 learning of the Perfekt construction with gehen, explicit processes seem to function as a control parameter.

Despite their apparent power, explicit processes are not only potentially facilitative, but also taxing. Indeed, they may be too taxing at times and thus have (temporarily) debilitative effects. The application of explicit knowledge may lead to cognitive overload, if a large number of open slots in a schematic construction needs to be filled. The application of explicit knowledge, possibly in conjunction with L1 influence, may also lead to overgeneralization, as exemplified by H's attempt to construct a Perfekt version of Das geht (nicht). In dynamic systems terms, this phenomenon can be understood as overshooting, that is, rapid changes in early developmental stages are observed, but these changes may go beyond the system's “eventual stable pattern or attractor, [may make it] oscillate for a while, and finally arrive at a stable point" (Howe \& Lewis, 2005, p. 249). This seems to be exactly what was observed in H's case. 


\section{Notes}

${ }^{1}$ The terms 'schematic construction' and '(abstract) constructional schema' are used interchangeably, in accordance with the literature cited in this paper.

${ }^{2}$ Research on L2 speech processing regards self-repair as the overt manifestation of monitoring (with self-repair prior to articulation considered covert), in accordance with the perceptual loop model of monitoring (e.g., Levelt, 1999). L2 speech production is seen as less automatic than L1 speech production, with monitoring and self-repair requiring attention, effort, and conscious control (e.g., Kormos, 2006), that is, characteristics associated with explicit processes as defined in this paper. In addition, it has been proposed that adult L2 learners make "conscious decisions concerning the implementation" of self-corrections (Kormos, 2006, p. 131), that is, they deliberately choose whether or not to self-correct in certain situations.

${ }^{3}$ Some measures in Elder and Manwaring (2004) yielded correlation coefficients from around $r=.6$ to .7 , others yielded non-significant results.

${ }^{4}$ To the best of my knowledge, there is no published research on the L2 development of German Perfekt constructions involving the verbs gehen and fahren. Existing research on developmental sequences in L2 German that includes analyses of the use of the Perfekt more generally has been primarily concerned with the acquisition of word order and finiteness (e.g., Dimroth, 2008; Klein \& Perdue, 1992; Meisel, Clahsen, \& Pienemann, 1981; Pienemann, 1999). The theoretical assumptions and, accordingly, the units of analysis 
employed are fundamentally different from the approach taken in the present study, and findings therefore cannot inform each other directly. In particular, existing research has assumed an essentially linear and cumulative developmental process, and, in accordance with this, researchers set out to uncover and describe discrete stages. Moreover, researchers typically assumed that before a certain stage in the sequence can be reached, the learner must have mastered the previous stage. This approach is in direct contrast to the usage-based perspective, which emphasizes the non-linear nature of the developmental process, though without denying the possibility of temporary periods of stability of parts of the L2 system (Larsen-Freeman, 1997, 2006).

${ }^{5}$ The fact that the researcher was also the tutor in this study has both potential advantages and potential disadvantages. Full control over the study was advantageous, enabling me to implement the desired focus-on-form approach without having to brief, train and rely on a third party. In addition, the practical challenges of conducting a longitudinal study were reduced, since it was not necessary to find, remunerate and retain a teacher who would be willing and able to cooperate with the project over a number of years. On the other hand, there is the potential danger of bias: the researcher's interests may be reflected in their actions and behavior as a tutor. In accordance with the accepted tenets of appropriate research methodology, every effort was made to reduce any such bias as much as possible (Mason, 1996; Silverman, 2000). At the same time, the interaction between researcher/tutor and participant will have led to a certain (mutual) influence. This may be regarded as a natural consequence of human interaction which cannot be avoided altogether and therefore needs to be acknowledged (Rapley, 2004).

\footnotetext{
${ }^{6}$ At this point in the study, the participant indicated that he wished to take a break from being recorded. Data collection resumed when the participant stated that he was ready to continue.
} 
${ }^{7}$ A reviewer suggested that the participant may have rehearsed or pre-planned his speech as the same prompt was used throughout. On occasion, the participant did indeed ask to be given a moment to gather his thoughts and try to recall the events of the previous day before the recording device was switched on. The requested time was always granted, but it never amounted to more than about 20 seconds. It is acknowledged that the participant may have pre-planned the first utterances of his subsequent production at this point or at an earlier point, for instance, prior to the lesson. However, once the tutor responded with follow-up questions, the participant had little opportunity for making use of any pre-planned speech because the follow-up questions were not predictable.

${ }^{8}$ Quotes from the data set have been edited for easy readability: filled pauses, retraced words, etcetera have been removed, except in cases where the precise quality of speech was to be retained for illustration purposes; [/] indicates retracing, [//] self-correction, [///] reformulation, with retraced/self-corrected/reformulated material shown in angled brackets. A gloss in idiomatic English is given below each German quote, regardless of the accuracy or idiomaticity of the L2 utterance. Where appropriate, incorrect German forms are marked by an asterisk.

${ }^{9}$ Bimodal attractors are in evidence when a learner alternates between two different forms to express the same meaning (see also Larsen-Freeman, 2006). This instability might precede a phase shift, that is, a major change in the learner's system, and pedagogical intervention might be particularly effective at this point (Larsen-Freeman \& Cameron, 2008).

${ }^{10}$ The reverse pattern does not occur, that is, fahren is never overgeneralized to gehen contexts.

\section{References}


Absi, Z. (2014). Metalinguistic knowledge and speaking proficiency in Syrian university-level learners of English. Unpublished $\mathrm{PhD}$ thesis, University of Essex.

Akakura, M. (2012). Evaluating the effectiveness of explicit instruction on implicit and explicit L2 knowledge. Language Teaching Research, 16, 9-37.

Albrecht, U., Dane, D., Fandrych, C., Grüßhaber, G., Henningsen, U., Kilimann, A., et al. (2001). Passwort Deutsch 2. Stuttgart: Klett.

Alderson, J. C., Clapham, C., \& Steel, D. (1997). Metalinguistic knowledge, language aptitude and language proficiency. Language Teaching Research, 1, 93-121.

Anderson, J. R. (2005). Cognitive psychology and its implications (6th ed.). New York: Worth Publishers.

Coggle, P., \& Schenke, H. (1998). Willkommen! The new course in German for adult beginners. London: Hodder \& Stoughton.

Collins, L., Trofimovich, P., White, J., Cardoso, W., \& Horst, M. (2009). Some input on the easy/difficult grammar question: An empirical study. Modern Language Journal, 93, 336-353.

de Bot, K., Lowie, W., \& Verspoor, M. (2007). A dynamic systems theory approach to second language acquisition. Bilingualism: Language and Cognition, 10, 7-21.

DeKeyser, R. M. (2005). What makes learning second-language grammar difficult? A review of issues. Language Learning, 55(Supplement1), 1-25.

Dimroth, C. (2008). Age effects on the process of L2 acquisition? Evidence from the acquisition of negation and finiteness in L2 German. Language Learning, 58, 117150.

Dörnyei, Z. (2009). The psychology of second language acquisition. Oxford, UK: Oxford University Press. 
Duff, P. A. (2008). Case study research in applied linguistics. New York: Lawrence Erlbaum.

Elder, C., \& Manwaring, D. (2004). The relationship between metalinguistic knowledge and learning outcomes among undergraduate students of Chinese. Language Awareness, $13,145-162$.

Elder, C., Warren, J., Hajek, J., Manwaring, D., \& Davies, A. (1999). Metalinguistic knowledge: How important is it in studying a language at university? Australian Review of Applied Linguistics, 22, 81-95.

Ellis, N. C. (2002). Reflections on frequency effects in language processing. Studies in Second Language Acquisition, 24, 297-340.

Ellis, N. C. (2005). At the interface: Dynamic interactions of explicit and implicit language knowledge. Studies in Second Language Acquisition, 27, 305-352.

Ellis, N. C. (2006). Selective attention and transfer phenomena in L2 acquisition: Contingency, cue competition, salience, interference, overshadowing, blocking, and perceptual learning. Applied Linguistics, 27, 164-194.

Ellis, N. C. (2011). Implicit and explicit SLA and their interface. In C. Sanz \& R. P. Leow (Eds.), Implicit and explicit language learning: Conditions, processes, and knowledge in SLA and bilingualism (pp. 35-47). Washington, DC: Georgetown University Press.

Ellis, N. C., \& Sagarra, N. (2010). The bounds of adult language acquisition. Studies in Second Language Acquisition, 32, 553-580.

Ellis, R. (2004). The definition and measurement of L2 explicit knowledge. Language Learning, 54, 227-275.

Ellis, R. (2005). Measuring implicit and explicit knowledge of a second language: A psychometric study. Studies in Second Language Acquisition, 27, 141-172. 
Ellis, R. (2006). Modelling learning difficulty and second language proficiency: The differential contributions of implicit and explicit knowledge. Applied Linguistics, 27, 431-463.

Eskildsen, S. W. (2009). Constructing another language: Usage-based linguistics in second language acquisition. Applied Linguistics, 30, 335-357.

Eskildsen, S. W. (2012). L2 negation constructions at work. Language Learning, 62, 335372.

Flyvbjerg, B. (2004). Five misunderstandings about case-study research. In C. Seale, G. Gobo, J. F. Gubrium, \& D. Silverman (Eds.), Qualitative research practice (pp. 420434). London: Sage.

Goldberg, A. E. (1995). Constructions: A construction grammar approach to argument structure. Chicago: University of Chicago Press.

Goldberg, A. E. (2003). Constructions: A new theoretical approach to language. Trends in Cognitive Sciences, 7, 219-224.

Golonka, E. M. (2006). Predictors revised: Linguistic knowledge and metalinguistic awareness in second language gain in Russian. Modern Language Journal, 90, 496505.

Hernandez, A., Li, P., \& MacWhinney, B. (2005). The emergence of competing modules in bilingualism. Trends in Cognitive Sciences, 9, 220-225.

Howe, M. L., \& Lewis, M. D. (2005). The importance of dynamic systems approaches for understanding development. Developmental Review, 25, 247-251.

Hu, G. (2011). Metalinguistic knowledge, metalanguage, and their relationship in L2 learners. System, 39, 63-77. 
Hulstijn, J. H. (2005). Theoretical and empirical issues in the study of implicit and explicit second-language learning: Introduction. Studies in Second Language Acquisition, 27, $129-140$.

Jackson, C. N. (2007). The use and non-use of semantic information, word order, and case markings during comprehension by L2 learners of German. Modern Language Journal, 91, 418-432.

Kemmer, S., \& Barlow, M. (2000). Introduction: A usage-based conception of language. In M. Barlow \& S. Kemmer (Eds.), Usage-based models of language (pp. vii-xxviii). Stanford, CA: CSLI.

Klein, W., \& Perdue, C. (1992). Utterance structure: Developing grammars again. Amsterdam: John Benjamins.

Kormos, J. (2006). Speech production and second language acquisition. Mahwah, NJ: Lawrence Erlbaum.

Langacker, R. W. (1991). Concept, image, and symbol: The cognitive basis of grammar. Berlin: Mouton de Gruyter.

Langacker, R. W. (1998). Conceptualization, symbolization, and grammar. In M. Tomasello (Ed.), The new psychology of language: Cognitive and functional approaches to language structure (Vol. 1, pp. 1-40). Mahwah, NJ: Lawrence Erlbaum.

Langacker, R. W. (2000). A dynamic usage-based model. In M. Barlow \& S. Kemmer (Eds.), Usage-based models of language (pp. 1-64). Stanford, CA: CSLI.

Larsen-Freeman, D. (1997). Chaos/complexity science and second language acquisition. Applied Linguistics, 18, 141-165.

Larsen-Freeman, D. (2006). The emergence of complexity, fluency, and accuracy in the oral and written production of five Chinese learners of English. Applied Linguistics, 27, $590-619$. 
Larsen-Freeman, D., \& Cameron, L. (2008). Complex systems and applied linguistics.

Oxford, UK: Oxford University Press.

Levelt, W. J. M. (1999). Producing spoken language: A blueprint of the speaker. In C. M.

Brown \& P. Hagoort (Eds.), The neurocognition of language (pp. 83-122). Oxford,

UK: Oxford University Press.

Macaro, E., \& Masterman, L. (2006). Does intensive explicit grammar instruction make all the difference? Language Teaching Research, 10, 297-327.

MacWhinney, B. (1997). Second language acquisition and the competition model. In A. M. B. de Groot \& J. F. Kroll (Eds.), Tutorials in bilingualism: Psycholinguistic perspectives (pp. 113-142). Mahwah, NJ: Lawrence Erlbaum.

MacWhinney, B. (2000). The CHILDES project: Tools for analyzing talk, Vol. 1: Tanscription format and programs (3rd ed.). Mahwah, NJ: Lawrence Erlbaum.

MacWhinney, B. (2004). A multiple process solution to the logical problem of language acquisition. Journal of Child Language, 31, 883-914.

MacWhinney, B. (2012). The logic of the Unified Model. In S. M. Gass \& A. Mackey (Eds.), Handbook of second language acquisition (pp. 211-227). New York: Routledge.

Mason, J. (1996). Qualitative researching. London: Sage.

Meisel, J., Clahsen, H., \& Pienemann, M. (1981). On determining develomental stages in natural second language acquisition. Studies in Second Language Acquisition, 18, 109-135.

Miles, M. B., \& Huberman, A. M. (1994). Qualitative data analysis (2nd ed.). Thousand Oaks, CA: Sage.

Norris, J. M., \& Ortega, L. (2001). Does type of instruction make a difference? Substantive findings from a meta-analytic review. Language Learning, 51, 157-213. 
Pienemann, M. (1999). Language processing and second language development: Processability theory. Amsterdam: John Benjamins.

Rapley, T. (2004). Interviews. In C. Seale, G. Gobo, J. F. Gubrium, \& D. Silverman (Eds.), Qualitative research practice (pp. 15-33). London: Sage.

Roehr-Brackin, K. (forthcoming). Explicit knowledge about language in L2 learning: A usage-based perspective. In P. Rebuschat (Ed.), Implicit and explicit learning of languages. Amsterdam: John Benjamins.

Roehr, K. (2008). Metalinguistic knowledge and language ability in university-level L2 learners. Applied Linguistics, 29, 173-199.

Roehr, K., \& Gánem-Gutiérrez, G. A. (2009). Metalinguistic knowledge: A stepping stone towards L2 proficiency? In A. Benati (Ed.), Issues in second language proficiency (pp. 79-94). London: Continuum.

Ryan, G. W., \& Bernard, H. R. (2000). Data management and analysis methods. In N. K. Denzin \& Y. S. Lincoln (Eds.), Handbook of qualitative research (2nd ed., pp. 769802). Thousand Oaks, CA: Sage.

Scheffler, P., \& Cinciała, M. (2011). Explicit grammar rules and L2 acquisition. ELT Journal, 65, 13-23.

Silverman, D. (2000). Doing qualitative research. London: Sage.

Spada, N., \& Tomita, Y. (2010). Interactions between type of instruction and type of language feature: A meta-analysis. Language Learning, 60, 263-308.

Spoelman, M., \& Verspoor, M. (2010). Dynamic patterns in development of accuracy and complexity: A longitudinal cse study in the acquisition of Finnish. Applied Linguistics, 31, 532-553.

Taylor, J. R. (2002). Cognitive grammar. Oxford, UK: Oxford University Press. 
Terrell, P., Schnorr, V., Morris, W. V. A., \& Breitsprecher, R. (Eds.). (1999) Collins German-English English-German Dictionary (4th ed.). Glasgow, UK: Harper Collins. Tomasello, M. (2003). Constructing a language: A usage-based theory of language acquisition. Cambridge, MA: Harvard University Press.

Tomasello, M. (2005). Beyond formalities: The case of language acquisition. The Linguistic Review, 22, 183-197.

Verspoor, M. H., de Bot, K., \& Lowie, W. (Eds.). (2011). A dynamic approach to second language development: Methods and techniques. Amsterdam: John Benjamins.

\section{Supporting Information}

Additional Supporting Information may be found in the online version of this article at the publisher's website:

Appendix S1. Description of the instructional approach on the Perfekt followed during the classes (3 years and 4 months)

Appendix S2. Developmental sequence of Perfekt constructions with fahren with detailed exemplification

Appendix S3. Perfekt constructions with gehen with detailed exemplification 


\section{Tables}

Table 1 Constructional schema A (fahren): nach-location/nach-Hause/preposition-location construction

Stage 1

Subj aux (zurück/weiter/los) nach [location]/nach Hause

gefahren

[Adverbial]

aux subj (zurück/weiter/los) nach [location]/nach Hause

gefahren

Stage 2 Subj aux (zurück/weiter/los) nach [location]/nach Hause

(weiter/los) gefahren

[Adverbial] aux subj (zurück/weiter/los) nach [location]/nach Hause

(weiter/los) gefahren

Stage 3 Subj aux (zurück/weiter/los) nach/zu [location]/nach Hause (weiter/los) gefahren aux subj (zurück/weiter/los) nach/zu [location]/nach Hause (weiter/los) gefahren

$\begin{array}{lll}\text { Subj aux [adverbial] } & \text { (zurück/weiter/los) [preposition] [location] } & \text { (weiter/los) gefahren } \\ \text { [Adverbial] aux subj } & \text { (zurück/weiter/los) [preposition] [location] } & \text { (weiter/los) gefahren }\end{array}$


Table 2 Constructional schema B (fahren): in-die-Stadt construction

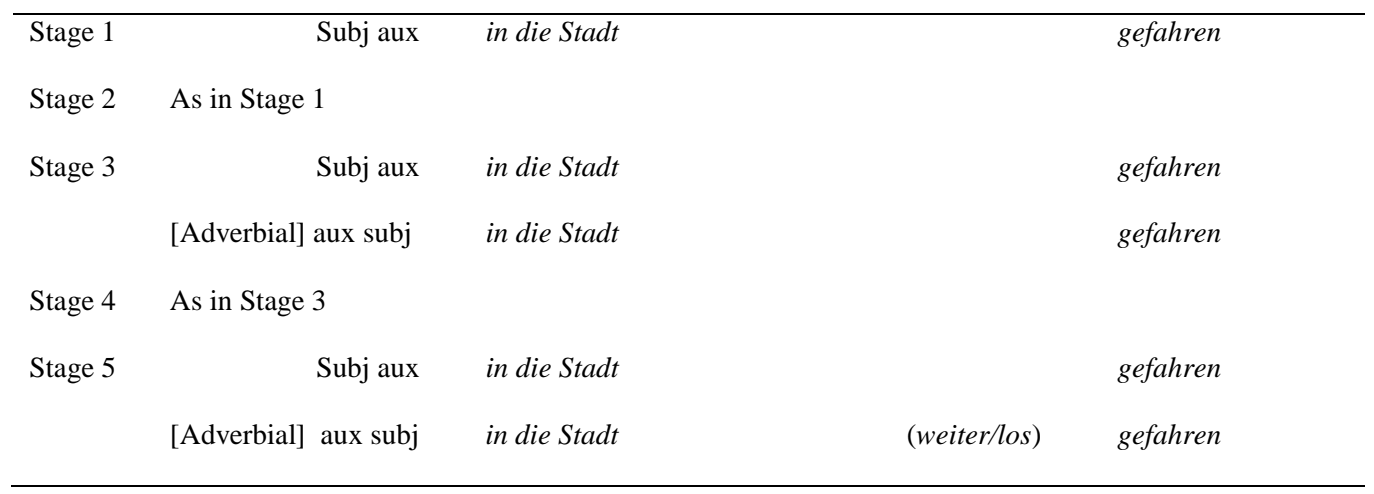


Table 3 Constructional schema C (fahren): means-of-transport construction

\begin{tabular}{llll}
\hline Stage 1 & No observed use & \\
Stage 2 & Subj aux $\quad$ mit $[$ means of transport] & (von [location] $) \quad($ nach/zu [location] $)$ & gefahren \\
Stage 3 & As in Stage 2 \\
Stage 4 & As in Stage 2 \\
Stage 5 & As in Stage 2
\end{tabular}


EXPLICIT PROCESSES FROM A USAGE-BASED PERSPECTIVE 5

Table 4 Constructional schema D (fahren): drive construction

\begin{tabular}{lll}
\hline Stage 1 & No observed use & \\
Stage 2 & No observed use & \\
Stage 3 & No observed use & \\
Stage 4 & Subj aux & gefahren \\
Stage 5 & Subj aux $\quad$ [adverbial] & gefahren \\
\hline
\end{tabular}


Table 5 Constructional schemas A and B (gehen): preposition-location and walk constructions

\begin{tabular}{|c|c|c|c|c|}
\hline A & [Adverbial] & $\begin{array}{l}\text { aux subj ([adverbial]) } \\
\text { Subj aux ([adverbial]) }\end{array}$ & $\begin{array}{l}\text { [preposition] [location] } \\
\text { [preposition] [location] }\end{array}$ & $\begin{array}{l}\text { ([particle]) gegangen } \\
\text { ([particle]) gegangen }\end{array}$ \\
\hline B & Subj aux & [adverbial] & & gegangen \\
\hline
\end{tabular}




\section{Appendix S1}

\section{Description of the instructional approach on the Perfekt followed during the classes (3 years and 4 months)}

The participant $\mathrm{H}$ encountered the main meanings of the verbs gehen ("go", "walk") and fahren ("go", "drive", "ride", "sail”, i.e., in short, "go by vehicle”) from Unit 5 in his first textbook (Willkommen!) onwards. I pointed out differences and similarities between L1 and L2 use of the two verbs. The Perfekt construction was first introduced in class as we worked through Unit 8 of the same textbook, approximately two months before the start of data collection, which began when we reached the final unit, Unit 12 . Through the metalinguistic descriptions in the textbook and my supplementary explanations, $\mathrm{H}$ learned that in spoken German, the Perfekt tense is typically used to recount past events, except with modal verbs and the verbs sein ("be") and haben ("have"), although there is some regional variation, with speakers of southern dialects showing a stronger preference for the Perfekt in all contexts than speakers of northern dialects.

With regard to the formation of the Perfekt, Unit 8 of Willkommen! introduces the various forms of German past participles as well as pedagogical grammar rules pertaining to their formation, including the forms of the two verbs under investigation (gehen $\rightarrow$ gegangen; fahren $\rightarrow$ gefahren). Working with the textbook in class and through the supplementary comments I provided, $\mathrm{H}$ also encountered pedagogical grammar rules about the required auxiliary verb in Perfekt constructions. Essentially, these pedagogical grammar rules state that verbs denoting directional movement or a change of state (as well as a few other verbs) combine with a form of sein ("be") in the Perfekt. As the group of German verbs taking a form of sein in the Perfekt is relatively small, with the majority of verbs taking a form of haben ("have"), metalinguistic descriptions aimed at L2 learners typically focus on 
verbs combining with sein, while treating verbs combining with haben as the default requiring no further comment. The textbooks we used in class took the same approach, and so did I. (It should be noted that there is also regional variation in the choice of auxiliary verbs in the Perfekt, with some speakers of southern dialects making 'non-standard' use of a form of sein when the textbook standard prefers a form of haben. As a speaker of a northern dialect I do not use the non-standard variant, and it did not occur in H's learning materials.) As before, I discussed with $\mathrm{H}$ differences between $\mathrm{L} 1$ and $\mathrm{L} 2$, in this instance with regard to the formation and use of the German Perfekt compared with the English perfect tense.

The pedagogical grammar rules and conventions of German Perfekt form and usage, though first introduced at a certain point in time, were recycled subsequently at irregular intervals, in accordance with the participant's needs. For instance, when H completed grammar exercises or had questions about the Perfekt (or indeed about any other grammar point), I discussed the issue with him and provided further explanations. When I noticed repeated mistakes or difficulties, or when $\mathrm{H}$ asked whether something he had said or written was correct, I provided feedback. Forms and usage of the Perfekt was also the grammatical focus of the first unit in H's second textbook, Passwort Deutsch 2; this resulted in further practice of the Perfekt. 


\section{Appendix S2}

\section{Developmental sequence of Perfekt constructions with fahren with detailed exemplification}

Stage $1(\mathrm{~S} 2-\mathrm{S} 5)$

A1 Subj aux (zurück/weiter/los) nach [location]/nach Hause

gefahren

A2 [Adverbial] aux subj

B

Subj aux in die Stadt

gefahren

\section{Examples}

$\mathrm{A}=$ nach-location/nach-Hause construction:

(1) STU: Wir sind nach E. gefahren. (S2)

We went/drove to $\mathrm{E}$.

(2) STU: Und dann sind wir zurück nach Hause gefahren. (S3)

And then we went/drove back home.

$\mathrm{B}=$ in-die-Stadt construction:

(3) STU: Wir sind in die Stadt gefahren. (S4)

We went/drove into town.

\section{Stage 2 (S6-S17)}
A1 Subj aux
(zurück/weiter/los) nach [location]/nach Hause (weiter/los)
gefahren
A2 [Adverbial] aux subj(zurück/weiter/los) nach [location]/nach Hause (weiter/los)
gefahren
B Subj aux
in die Stadt
gefahren 
C Subj aux mit [means of transport] (von [location]) $($ nach/zu [location]) gefahren

\section{Examples}

$\mathrm{A}=$ nach-location/nach-Hause construction:

(4) STU: Um halb drei bin ich nach C. losgefahren. (S7)

At half past two I left for C.

(5) STU: So sind wir weitergefahren. (S9)

So we went/drove on.

$\mathrm{C}=$ Means-of-transport construction:

(6) STU: Wir sind mit dem Bus *von Flughafen *nach in der Nähe vom Hotel gefahren. (S8)

We took the bus from the airport to near the hotel.

(7) STU: Dann sind wir mit der Straßenbahn nach B. gefahren. (S8)

Then we took the tram to B.

\section{Stage 3 (S18-S25)}

A1 Subj aux (zurück/weiter/los) nach/zu [location]/nach Hause (weiter/los) gefahren A2 [Adverbial] aux subj(zurück/weiter/los) nach/zu [location]/nach Hause (weiter/los) gefahren

B1 Subj aux in die Stadt gefahren

B2 [Adverbial] aux subj in die Stadt gefahren

C Subj aux mit [means of transport] (von [location]) (nach/zu [location]) gefahren

\section{Examples}

$\mathrm{A}=$ nach/zu-location/nach-Hause construction: 
(8) STU: Um sieben Uhr bin ich nach C. zum Fechtclub gefahren. (S19)

At seven o'clock I went/drove to C. to the fencing club.

(9) STU: Danach sind wir zu B. [name of shop] gefahren. (S23)

Then we went/drove to B.

$\mathrm{B}=$ in-die-Stadt construction:

(10) STU: Um halb elf vielleicht sind wir in die Stadt losgefahren. (S22)

At half past ten perhaps we set off into town.

Stage 4 (S26-S50)
A1 Subj aux
(zurück/weiter/los)
preposition [location] (weiter/los)
gefahren
A2 [Adverbial] aux subj(zurück/weiter/los)
preposition [location] (weiter/los) gefahren
B1 Subj aux in die Stadt
gefahren
B2 [Adverbial] aux subj in die Stadt
gefahren
C Subj aux
mit [means of transport] (von [location]) (nach/zu [location])
gefahren
D Subj aux
gefahren

\section{Examples}

A = preposition-location construction:

(11) STU: Dann sind wir zurück ins Dorf gefahren. (S26)

Then we went/drove back into the village.

(12) STU: Und dann sind wir durch F. gefahren. (S27)

And then we went/drove through $\mathrm{F}$.

$\mathrm{B}=$ in-die-Stadt construction: 
(13) STU: Und danach sind wir in die Stadt gefahren. (S37)

And then we went/drove into town.

$\mathrm{D}=$ drive construction:

(14) STU: Du *hast gefahren. (S27)

You were driving.

\section{Stage 5 (from S51)}

A1 Subj aux [adverbial] (zurück/weiter/los) [preposition] [location] (weiter/los) gefahren

A2 [Adverbial] aux subj (zurück/weiter/los) [preposition] [location] (weiter/los) gefahren

B1 Subj aux in die Stadt gefahren

B2 [Adverbial] aux subj in die Stadt $\quad$ (weiter/los) gefahren

C Subj aux mit [means of transport] (von [location]) $($ nach/zu [location]) gefahren

$\begin{array}{lll}\text { D Subj aux } \quad \text { [adverbial] } & \text { gefahren }\end{array}$

\section{Examples}

$\mathrm{A}=$ preposition-location construction:

(15) STU: Wir sind zuerst zu einer Tankstelle gefahren. (S51)

We first went/drove to a petrol station.

(16) STU: Und wir sind ziemlich langsam zurück nach C. gefahren. (S62)

And we went/drove back to C. quite slowly.

$\mathrm{B}=$ in-die-Stadt construction:

(17) STU: Und wir sind in die Stadt gefahren. (S60)

And we went/drove into town. 
(18) STU: Und dann sind wir weiter in die Stadt gefahren. (S82)

And then we went/drove on into town.

$\mathrm{D}=$ drive construction:

(19) STU: Ich *habe nie in N. gefahren. (S51)

I've never driven in $\mathrm{N}$. 


\section{Appendix S3}

\section{Perfekt constructions with gehen with detailed exemplification}

\section{Single stage (by S8)}

A1 [Adverbial] aux subj ([adverbial]) [preposition] [location] ([particle]) gegangen

A2 Subj aux ([adverbial]) [preposition] [location] ([particle]) gegangen

B Subj aux [adverbial] gegangen

\section{Examples}

$\mathrm{A}=$ preposition-location construction:

(20) STU: Und dann sind wir in die Stadt gegangen. (S1)

And then we went into town.

(21) STU: Danach sind wir zu T. [name of shop] gegangen. (S1)

Afterwards we went to T.'s.

(22) STU: Dann sind wir wieder zurïck zum Auto gegangen. (S3)

Then we went back to the car.

(23) STU: Und dann sind wir weitergegangen. (S6)

And then we went on.

(24) STU: So sind wir zurückgegangen (...) und in der Nähe am Wasser spazierengegangen. (S6)

So we went back and went for a walk nearby along the water.

(25) STU: Später sind wir in der Nähe vom Hotel spazierengegangen. (S8) Later we went for a walk near the hotel.

(26) STU: Wir sind in die Kneipe gegangen. (S3)

We went to the pub. 
(27) STU: Wir sind in der Stadt spazierengegangen. (S4)

We went for a walk in the city.

(28) STU: Wir sind in (...) ein kleines Café gegangen. (S5)

We went to (...) a small cafe.

(29) STU: Ich bin in die Küche gegangen. (S6)

I went into the kitchen.

(30) STU: Und dann sind wir zurück durch die Stadt gegangen. (S21)

And then we went back through the town.

(31) STU: Aber wir sind wieder gegangen. (S22)

But we left again.

(32) STU: Ja, und dann sind wir am Strand spazierengegangen. (S25)

Yes, and then we went for a walk by the beach.

(33) STU: Wir sind mit meiner Familie ins Restaurant gegangen. (S28)

We went for a meal with my family.

(34) STU: Dann sind wir direkt zum Auto gegangen. (S30)

Then we went straight to the car.

(35) STU: Und wir sind ein bisschen am Fluss entlang gegangen. (S63)

And we walked along the river for a bit.

(36) STU: Wir sind am Strand entlang nach F. gegangen. (S67)

We walked along the beach to F.

$\mathrm{B}=$ walk construction

(40) STU: Wir sind um drei Meilen gegangen. (S8)

We walked about three miles. 